\title{
Altered Toxicities of Fatty Acid Salts in Green Paramecia Cultured in Different Waters
}

\author{
Takashi Kadono ${ }^{\mathrm{a}}$, Kazuya Uezu ${ }^{\mathrm{a}}$, Toshikazu Kosaka ${ }^{\mathrm{b}}$, and Tomonori Kawano ${ }^{\mathrm{a}, *}$ \\ a Graduate School of Environmental Engineering, The University of Kitakyushu, Kitakyu- \\ shu 808-0135, Japan. Fax: +81(0)93-695-3304. E-mail: kawanotom@env.kitakyu-u.ac.jp \\ b Graduate School of Science, Hiroshima University, Higashi-Hiroshima 739-8526, Japan \\ * Author for correspondence and reprint requests \\ Z. Naturforsch. 61c, 541-547 (2006); received September 19/December 14, 2005
}

Detergents including fatty acid salts act as surface-active agents and thus possibly damage the plasma membrane structures of aquatic organisms. Therefore, when excess, the houseused and industrial outflows of such detergents into aquatic environments may have considerable impacts on the ecosystem. In this study, we propose the use of green paramecia (Paramecium bursaria) for assessing the acute toxicity of eight fatty acid salts ( $\mathrm{Na}$ and $\mathrm{K}$ salts of oleate, palmitate, laurate and myristate) under various water conditions. The Paramecium in the stationary phase were used for a toxicity assay carried out on 12-well microplates and the median lethal concentration $\left(\mathrm{LC}_{50}\right)$ was determined for each fatty acid salt. In the low mineral culture medium prepared with ultra-pure water, the $\mathrm{LC}_{50}$ for each fatty acid ranged from 5.8 to $144 \mathrm{ppm}(\mathrm{w} / \mathrm{v})$. The toxic levels of fatty acid salts differed in the following order: laurate, myristate $\geq$ oleate, palmitate. The toxic levels of oleate and palmitate salts were $c a$. 10 -fold lower than those of laurate and myristate salts. When river water and local tap water instead of ultra-pure water were used for culturing, the toxic levels of all fatty acid salts were drastically lowered compared to the low mineral condition by 30 - to 100 -fold $(198-660 \mathrm{ppm}$, w/v). Similar detoxification effect was observed when $\mathrm{Ca}$ or $\mathrm{Mg}$ was added to the low mineral culture media, indicating that the toxicity of fatty acid salts can be notably lowered as the mineral content increases. As we demonstrated that toxicities of fatty acid salts can be lowered in river water and tap water compared to the low mineral condition, some chemical substances behave differently in the different water conditions. Therefore, the use of natural waters reflecting the real environmental conditions in further collection of data on the ecotoxicity impacts of variety of chemicals is highly encouraged.

Key words: Bioassay, Green Paramecia, Fatty Acid Salt, Water Hardness

\section{Introduction}

Fatty acid salts (often being $\mathrm{Na}$ salts) are main components of soap which has been massively used in households and industries since the $18 \mathrm{th}$ century (Wolf et al., 2001). Fatty acid salts act as surface-active agents and thus possibly damage the plasma membrane structures of aquatic organisms (Kalmanzon et al., 1992). Therefore, the outflow of detergents including soap components as residential and industrial waste waters into aquatic environments may have considerable impacts on ecosystems. When fatty acid salts are added to hard water, insoluble and inert precipitates lacking surfactant activity are formed as a consequence of calcium ion- or magnesium ion-dependent formation of insoluble metallic soaps by replacing the sodium or potassium attached to the fatty acid with Ca or Mg (Kirsner and Froelich, 1998). Thus, toxicity of fatty acid salts in water is likely dependent on the conditions of water.
In the United States, the toxic impacts of various chemicals to aquatic organisms and terrestrial organisms have been documented in the Ecotoxicology Database (ECOTOX) of the US EPA (U.S. Environmental Protection Agency, 2003). Toxicity assays of chemical pollutants using cultured mammalian cells have been developed and widely used (Bradlaw, 1986). In addition, a variety of ciliated and flagellated protozoa has been used as ecotoxicological bioindicators of chemical substances especially in aquatic environments such as the rivers, the ponds, the lakes and the ocean (Kawano et al., 2004a, 2005; Miyoshi et al., 2003). In this study, we propose the use of green paramecia (Paramecium bursaria) for assessing the acute toxicity of fatty acid salts under various water conditions. $P$. bursaria used here is widely habitable in freshwaters such as the rivers, lakes and ponds (Kosaka, 1991). Therefore, $P$. bursaria is an appropriate material for the study of chemical toxicity in micro-envi- 
ronment in fresh water. $P$. bursaria is a photosynthetic unicellular organism possessing several hundred cells of Chlorella-like endosymbiotic green algae in its cytoplasm and the communications between the host and symbiont for maintenance of symbiosis in $P$. bursaria have been well documented (Reisser, 1992). According to a co-evolution model, this symbiotic relationship between algal cells and the ciliate has been developed as a consequence of host cell's adaptation to the oxidative stress due to algal photosynthesis (Kawano et $a l ., 2004 b$ ). Thus, this organism may be a good indicator of chemical impacts to both algae and protozoan microorganisms. Since $P$. bursaria receives photosynthetic products from the green algae, culturing and long term maintenance of $P$. bursaria are relatively easier (under experimental light sources) compared to other ciliates (Kadono et al., 2004). This is another advantage of the use of this material.

\section{Materials and Methods}

\section{Organisms}

The green paramecia strain F1-1b (syngen 1, mating type I) was produced by conjugation of $\mathrm{KN}-15$ strain (syngen 1, mating type I) and BWK4 strain (syngen 1 , mating type IV) in our laboratory in spring 2003. The KN-15 and BWK-4 strains were originally collected from the Kinokawa river (Wakayama, Japan) and Lake Biwa (Shiga, Japan), respectively, in 2002. Prior to the toxicity assay, the mating test on the newly-conjugated stock (F1-1b) was carried out using four mature stocks, KN-15 (mating type I), BWK-16 (mating type II), KN-21 (mating type III), and BWK-4 (mating type IV) of $P$. bursaria syngen 1 . KN-21 and BWK-16 were originally collected from the Kinokawa river and the Lake Biwa, respectively, in 2002. P. bursaria strains were cultured in the medium made of the yeast extract-based nutrition mixture EBIOS (1 tablet/L; Asahi Food and Healthcare, Tokyo, Japan), after inoculation with the food bacterium Klebsiella pneumoniae, under a light cycle of $12 \mathrm{~h}$ light and $12 \mathrm{~h}$ dark with $\mathrm{ca} .3500 \mathrm{lux}(30 \mathrm{~cm}$ from the light source) of natural-white fluorescent light at $23{ }^{\circ} \mathrm{C}$. The EBIOS tablets $(250 \mathrm{mg}$ each) contain $94.2 \%(\mathrm{w} / \mathrm{w})$ dry yeast homogenates and $5.5 \%$ $(\mathrm{w} / \mathrm{w})$ carbohydrates. Concomitant minerals carried over by yeast cells namely potassium $1.9 \%$ $(\mathrm{w} / \mathrm{w})$, phosphate $1.6 \%(\mathrm{w} / \mathrm{w})$, calcium $0.26 \%(\mathrm{w} /$ w), magnesium $0.25 \%(\mathrm{w} / \mathrm{w})$, sodium $0.16 \%(\mathrm{w} / \mathrm{w})$ and others can be found in the tablets. The bacterized EBIOS medium was prepared by inoculating the medium with $K$. pneumoniae $1 \mathrm{~d}$ prior to the use in the ciliate culture.

\section{Fatty acid salts}

Eight natural fatty acid salts, namely sodium and potassium salts of oleate $\left[\mathrm{CH}_{3}-\left(\mathrm{CH}_{2}\right)_{7}-\mathrm{CH}=\right.$ $\left.\mathrm{CH}-\left(\mathrm{CH}_{2}\right)_{7}-\mathrm{COONa} / \mathrm{K}\right]$, palmitate $\left[\mathrm{CH}_{3}-\right.$ $\left.\left(\mathrm{CH}_{2}\right)_{14}-\mathrm{COONa} / \mathrm{K}\right]$, myristate $\left[\mathrm{CH}_{3}-\left(\mathrm{CH}_{2}\right)_{12}-\right.$ $\mathrm{COONa} / \mathrm{K}]$ and laurate $\left[\mathrm{CH}_{3}-\left(\mathrm{CH}_{2}\right)_{10}-\mathrm{COONa} /\right.$ $\mathrm{K}]$, were used. These fatty acid salts were of reagent levels and obtained form the Sabondama Soap Corporation (Kitakyushu, Japan). The fatty acids were first dissolved in ultra-pure water $(\geq 13$ $\mathrm{M} \Omega \cdot \mathrm{cm}^{-1}$ ) and diluted to concentrations 10 times greater than the required concentrations prior to addition to the culture. Then $100 \mu \mathrm{L}$ of the stock solutions of fatty acid salts were added to $900 \mu \mathrm{L}$ of culture.

\section{Waters and the culture media}

Three different waters, namely ultra-pure water $\left(\geq 13 \mathrm{M} \Omega \cdot \mathrm{cm}^{-1}\right)$, river water directly sampled from the Ongagawa river (Fukuoka, Japan), and Kitakyushu city tap water originated from the Ongagawa river, were used for preparing the EBIOS media. Prior to preparation of the EBIOS media, dechlorination of tap water was carried out by autoclaving $\left(121^{\circ} \mathrm{C}, 20 \mathrm{~min}\right)$. The mineral compositions in these waters and the media prepared form different waters were determined with an ionic chromatograph (DX-120; Dionex, CA).

\section{Toxicity assays}

Paramecium in the stationary phase were washed once with the EBIOS medium made up with the ultra-pure water and then twice with the EBIOS media made up with different waters to be used. The toxicity assay using green paramecia was carried out on 12-well microplates and the median lethal concentration $\left(\mathrm{LC}_{50}\right)$ was determined for each fatty acid salt. Each well of the microplates was filled with $900 \mu \mathrm{L}$ of the EBIOS media containing 100 Paramecium cells and $100 \mu \mathrm{L}$ of fatty acid salt solution $(0-1000 \mathrm{ppm}, \mathrm{w} / \mathrm{v})$ were added onto each well. Then the microplates were incubated for $12 \mathrm{~h}$ at $23{ }^{\circ} \mathrm{C}$ under continuous dark condition, and the number of living Paramecium cells was counted at the end of the incubation under a 
stereomicroscope (SMZ645; Nikon, Tokyo, Japan).

\section{Modification of water hardness}

For investigation of the relationship between the water hardness and the toxicity of fatty acid salts, $\mathrm{CaCl}_{2}$ as the source of calcium ions or $\mathrm{MgCl}_{2} \cdot 6 \mathrm{H}_{2} \mathrm{O}$ as the source of magnesium ions was added to the low mineral culture medium. The water hardness was adjusted to be between 12.5 and $400 \mathrm{mg} / \mathrm{L}$. The water hardness equivalent to the concentration of $\mathrm{CaCO}_{3}(\mathrm{mg} / \mathrm{L})$ was calculated as $100.1([\mathrm{Ca}](\mathrm{mg} / \mathrm{L}) / 40.1+[\mathrm{Mg}](\mathrm{mg} / \mathrm{L}) / 24.3)$, where 100.1, 40.1 and 24.3 represent the molecular weight of $\mathrm{CaCO}_{3}$, the atomic weight of $\mathrm{Ca}$ and the atomic weight of $\mathrm{Mg}$, respectively.

\section{Results and Discussion}

\section{Toxicity assay under low mineral condition}

The cell survival rates of $P$. bursaria exposed to fatty acid salt solutions for $12 \mathrm{~h}$ of incubation under low mineral (ultra-pure water) condition are shown in Figs. 1-4. We observed no notable difference between the toxicity of sodium salts and potassium salts of fatty acids. Treatment with high contents of fatty acid salts $(300 \mathrm{ppm}$ and $1000 \mathrm{ppm}, \mathrm{w} / \mathrm{v}$ ) completely killed the cells of Paramecium within $5 \mathrm{~min}$. When $P$. bursaria was treated with high contents of fatty acid salts, the plasma membrane of $P$. bursaria burst out and the cell structure was lost. After $12 \mathrm{~h}$ of incubation in the presence of lethal contents (over $\mathrm{LC}_{100}$ ) of fatty acid salts, the shape of $P$. bursaria was no longer observable. In contrast, when $P$. bursaria was treated with lethal concentrations of other chemicals such as heavy metals, the shape of dead cells retained intact (data not shown). The toxic levels of fatty acid salts differed in the following order: laurate $\left(\mathrm{LC}_{50} 5.8-6.7 \mathrm{ppm}, \mathrm{w} / \mathrm{v}\right)$, myristate $\left(\mathrm{LC}_{50}\right.$ 6.7-7.7 $\left.\mathrm{ppm}, \mathrm{w} / \mathrm{v}\right) \geq$ oleate $\left(\mathrm{LC}_{50} 52-\right.$ $59 \mathrm{ppm}, \mathrm{w} / \mathrm{v})$, palmitate $\left(\mathrm{LC}_{50} 40-144 \mathrm{ppm}, \mathrm{w} / \mathrm{v}\right)$ (see Table I). The cell survival percentage plotted against mole-based concentration instead of weight-based concentration of fatty acid salts also showed the same order of toxicity (data not shown). The toxic levels of oleate and palmitate salts were $c a$. 10 -fold lower than those of laurate and myristate salts. Among the salts of saturated fatty acids (palmitate, laurate, myristate), the $\mathrm{Na}$ salt of palmitate showed the lowest toxicity. In the presence of low contents of fatty acid salts (oleate
A
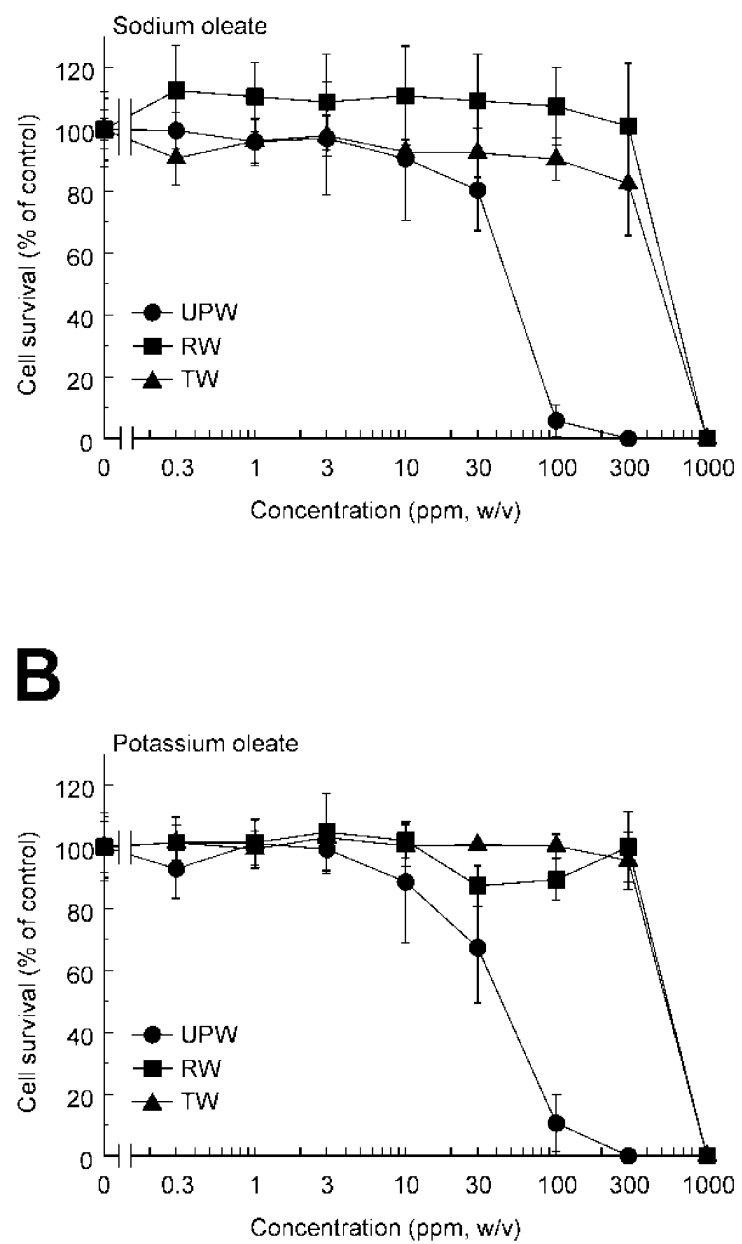

Fig. 1. The toxicity of sodium and potassium oleate in $P$. bursaria under various water conditions. Graphs show the cell survival rates after $12 \mathrm{~h}$ of exposure to sodium (A) and potassium (B) oleate. Each data point represents the mean of 3 experiments (each with 100 cells). Vertical bars represent S.D. $(n=3)$. UPW, RW and TW represent the ultra-pure water, river water and tap water conditions, respectively.

and palmitate $0.3-10 \mathrm{ppm}$; laurate and myristate $0.3-3 \mathrm{ppm}, \mathrm{w} / \mathrm{v})$, the viability and motility of $P$. bursaria were unchanged compared to the cells cultured in the absence of fatty acid salts. Assuming that the toxic impact of fatty acid salts is solely due to the damage of the membranes, there must be a threshold concentration of fatty acid salts for damaging the membrane structure. Obviously, fatty acid salt concentrations below such threshold 
A

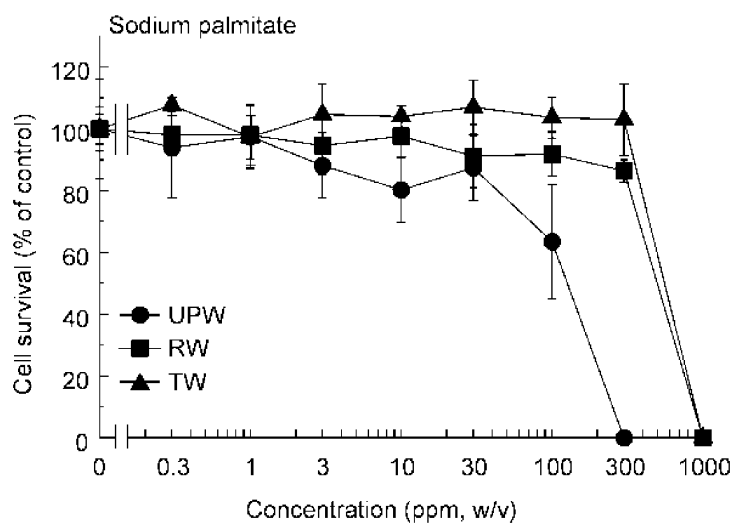

B

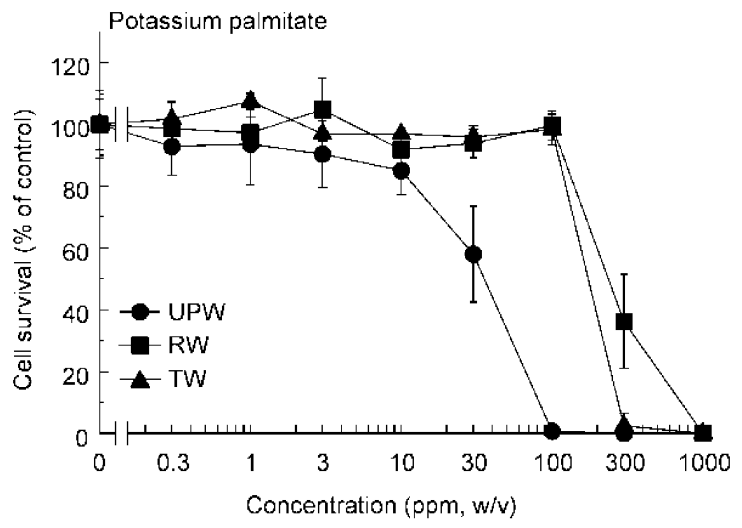

Fig. 2. The toxicity of sodium and potassium palmitate in $P$. bursaria under various water conditions. Graphs show the cell survival rates after $12 \mathrm{~h}$ of exposure to sodium (A) and potassium (B) palmitate. Each data point represents the mean of 3 experiments (each with 100 cells). Vertical bars represent S.D. $(n=3)$. UPW, RW and TW represent the ultra-pure water, river water and tap water conditions, respectively.

concentrations are not harmful to living cells. Since many of bio-toxicological assays using aquatic organisms are likely carried out in distilled water or pure water, the toxicities of fatty acid salts were also tested in ultra-pure water for comparison with the reported data for many chemicals. However, this laboratory water condition never reflects the water conditions in the actual environ-
A

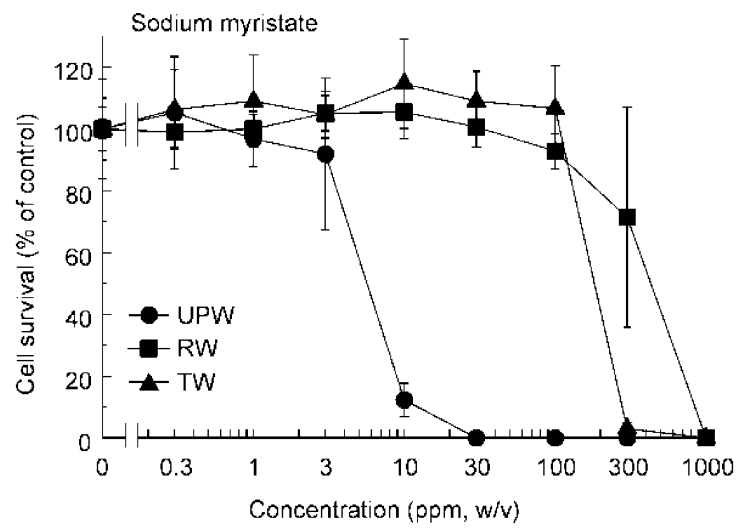

B

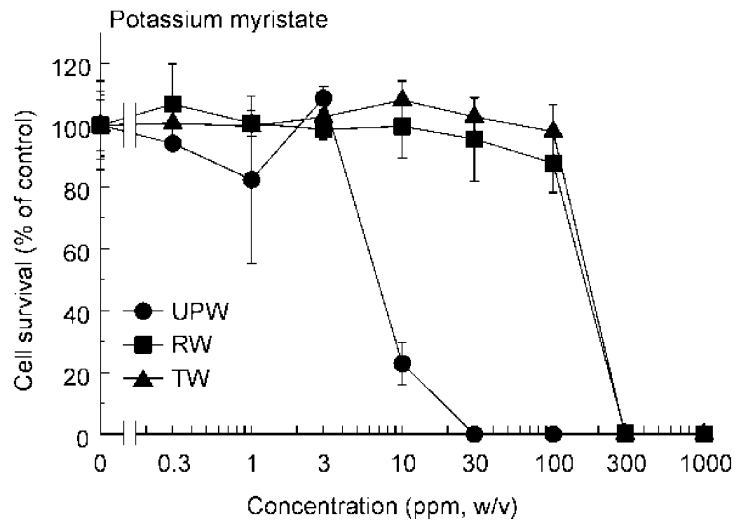

Fig. 3. The toxicity of sodium and potassium myristate in $P$. bursaria under various water conditions. Graphs show the cell survival rates after $12 \mathrm{~h}$ of exposure to sodium (A) and potassium (B) myristate. Each data point represents the mean of 3 experiments (each with 100 cells). Vertical bars represent S.D. $(n=3)$. UPW, RW and TW represent the ultra-pure water, river water and tap water conditions, respectively.

ments in nature. In the section below, the toxicities of fatty acid salts will be examined in natural river water and a local tap water originated from the river since some chemicals behave differently in the different water conditions and $P$. bursaria's most favored habitats in nature are the mineralized water environments such as rivers and lakes. In addition, the soaps are usually used in combina- 
$\Delta$

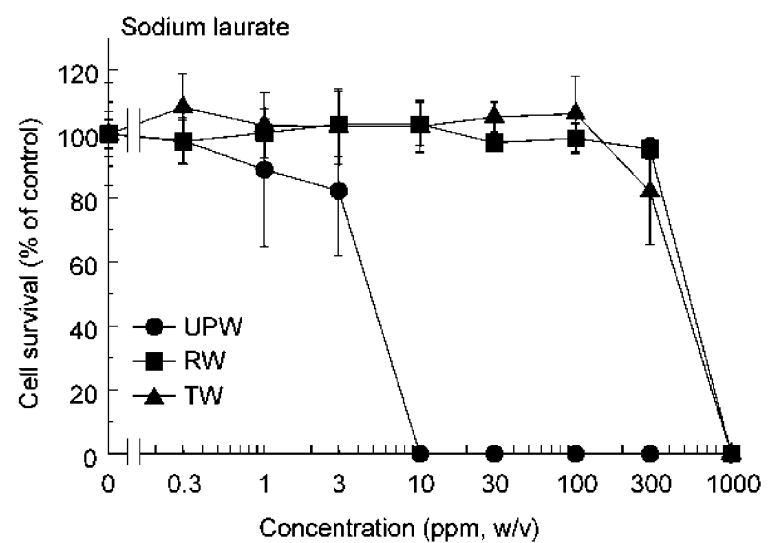

B

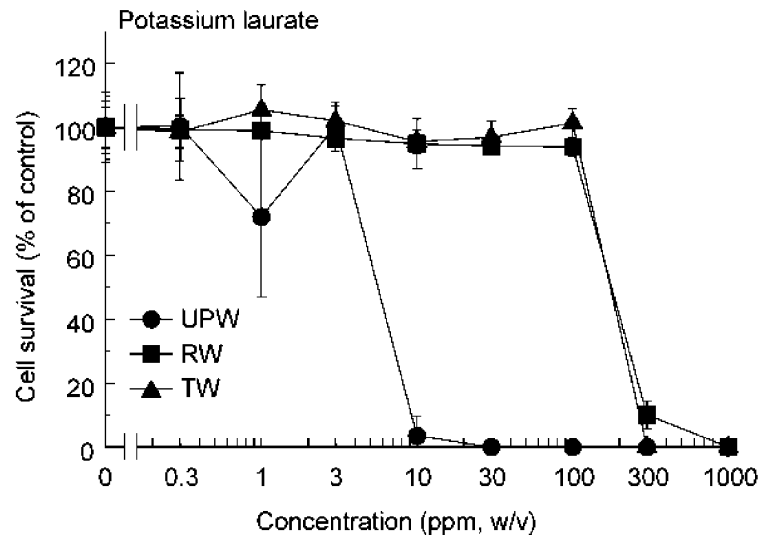

Fig. 4. The toxicity of sodium and potassium laurate in $P$. bursaria under various water conditions. Graphs show the cell survival rates after $12 \mathrm{~h}$ of exposure to sodium (A) and potassium (B) laurate. Each data point represents the mean of 3 experiments (each with 100 cells). Vertical bars represent S.D. $(n=3)$. UPW, RW and TW represent the ultra-pure water, river water and tap water conditions, respectively.

tion with tap water in both the industries and houses and the resultant release of soap components likely reaches the water environments such as rivers and lakes; therefore the tests in such water conditions are more favorable for understanding the actual impacts of these chemicals on the aquatic microorganisms.
Table I. $\mathrm{LC}_{50}(\mathrm{ppm}, \mathrm{w} / \mathrm{v})$ for fatty acid salts in $P$. bursaria cultured in different waters.

\begin{tabular}{lccc}
\hline Detergent & $\begin{array}{c}\text { Low mineral } \\
\text { medium }\end{array}$ & $\begin{array}{c}\text { River water } \\
\text { medium }\end{array}$ & $\begin{array}{c}\text { Tap water } \\
\text { medium }\end{array}$ \\
\hline Na oleate & 59 & 652 & 572 \\
Na palmitate & 144 & 595 & 660 \\
Na myristate & 6.7 & 508 & 210 \\
Na laurate & 5.8 & 631 & 572 \\
K oleate & 52 & 650 & 633 \\
K palmitate & 40 & 339 & 200 \\
K myristate & 7.7 & 230 & 198 \\
K laurate & 6.7 & 652 & 200 \\
\hline
\end{tabular}

Low mineral medium, river water medium and tap water medium were prepared by adding the nutrient tablets (EBIOS) into the ultra-pure water, river water and tap water, respectively. For details, see text. These values were graphically worked out from the data presented in Figs. $1-4$.

\section{Toxicity assays in river water and tap water}

Here, we used the river water and the Kitakyushu city local tap water instead of ultra-pure water for the preparation of ciliate culture medium (Figs. 1-4). The mineral compositions in these waters and culture media prepared were determined with an ionic chromatograph (Table II). The concentrations of most ions in the river water and tap water were almost identical. The culture media themselves prepared from the river water and tap water had no lethal effect on the survival of $P$. bursaria in the absence of fatty acid salts (data not shown). When Paramecium were exposed to high contents of fatty acid salts (1000 ppm, w/v), all Paramecium cells burst out and died within 5 min in both conditions. The toxic levels of all fatty acid salts under both water conditions were drastically lowered compared to the low mineral condition (ultra-pure water). The lethal concentrations $\left(\mathrm{LC}_{100}\right)$ of fatty acid salts after $12 \mathrm{~h}$ of incubation under these water conditions were 30 - to 100 -fold lower than those determined under low mineral water condition. The $\mathrm{LC}_{50}$ value for each fatty acid salt was also drastically lowered (Table I). The fatty acid salts readily react with cations (mainly calcium ions and magnesium ions) in water, and this results in the formation of insoluble precipitates of metallic soaps which are inert to the biomembranes since the $\mathrm{Ca} / \mathrm{Mg}$-replaced metallic soaps no longer possess the surfactant activity (Kirsner and Froelich, 1998). In the media prepared with river water and tap water, the concentration of $\mathrm{Ca}$ and $\mathrm{Mg}$ ions were 20- and 3-fold 
Table II. Ionic compositions in the waters and media used.

\begin{tabular}{|c|c|c|c|c|c|c|c|c|c|c|c|c|c|}
\hline \multirow{2}{*}{$\begin{array}{l}\text { Waters and } \\
\text { culture media }\end{array}$} & \multicolumn{13}{|c|}{ Ions $[\mathrm{mg} / \mathrm{L}]$} \\
\hline & $\mathrm{Li}^{+}$ & $\mathrm{Na}^{+}$ & $\mathrm{NH}_{4}^{+}$ & $\mathrm{K}^{+}$ & $\mathrm{Mg}^{2+}$ & $\mathrm{Ca}^{2+}$ & $\mathrm{F}^{-}$ & $\mathrm{Cl}^{-}$ & $\mathrm{NO}_{2}^{-}$ & $\mathrm{Br}^{-}$ & $\mathrm{NO}_{3}{ }^{-}$ & $\mathrm{PO}_{4}{ }^{3-}$ & $\mathrm{SO}_{4}{ }^{2-}$ \\
\hline Ultra-pure water & ND & ND & ND & ND & ND & ND & ND & ND & ND & ND & ND & ND & ND \\
\hline River water & ND & 17.93 & 0.60 & 3.69 & 5.74 & 28.07 & 0.10 & 17.97 & ND & ND & 6.67 & ND & 39.04 \\
\hline Tap water & ND & 20.20 & ND & 3.05 & 6.97 & 27.94 & 0.13 & 23.82 & ND & ND & 4.38 & ND & 57.96 \\
\hline Ultra-pure water + medium & ND & 7.54 & 1.16 & 3.43 & 2.19 & 1.40 & ND & 17.57 & ND & ND & 0.09 & 1.74 & 3.00 \\
\hline River water + medium & ND & 16.70 & ND & 6.30 & 7.91 & 25.59 & 0.56 & 18.87 & ND & ND & 11.95 & ND & 38.25 \\
\hline Tap water + medium & ND & 22.04 & 0.92 & 7.01 & 7.14 & 28.27 & 0.19 & 24.55 & ND & ND & 4.82 & ND & 64.33 \\
\hline
\end{tabular}

Ions in the waters and the culture media were determined with ionic chromatography as describe in the text. ND, below the detection limits. Since all the ionic contents in the ultra-pure water are below the detection limits, the detected ions in the "ultra-pure water + medium" must be solely due to addition of the EBIOS tablets.

higher than those in ultra-pure water-based culture medium, respectively (Table II). Under the river and tap water conditions, fatty acid salts may readily form the insoluble precipitates and therefore the toxicity of fatty acid salts becomes notably lower than that in the low mineral ultra-pure water condition.

\section{The relationship between the water hardness and} the toxicity of fatty acid salts

Since the toxicities of fatty acid salts in ultrapure water was much greater than those in river water and in tap water (Figs. 1-4), it is tempting to speculate that the toxicities of fatty acid salts were lowered by the presence of minerals as dis-

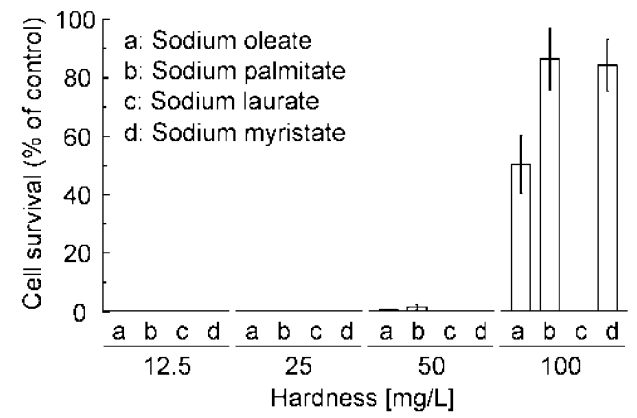

Fig. 5. The relationship between the toxicities of fatty acid salts and water hardness. Graphs show the cell survival rate of $P$. bursaria exposed to sodium fatty acids for $12 \mathrm{~h}$ under various water hardness adjusted using $\mathrm{CaCl}_{2}$. Vertical bars represent S.D. $(n=4)$. cussed above. To test this idea, we investigated the relationship between the water hardness (contents of $\mathrm{Ca}$ and $\mathrm{Mg}$ ions) and the toxicity of fatty acid salts. Adjustment of water hardness was carried out by addition of $\mathrm{CaCl}_{2}\left(\right.$ or $\left.\mathrm{MgCl}_{2} \cdot 6 \mathrm{H}_{2} \mathrm{O}\right)$ as the source of $\mathrm{Ca}^{2+}\left(\right.$ or $\left.\mathrm{Mg}^{2+}\right)$ to the ultra-pure waterbased low mineral toxicity assay medium. Fig. 5 shows the cell survival rate of $P$. bursaria exposed to the sodium salts of fatty acids for $12 \mathrm{~h}$ under various water hardnesses $(12.5,25,50$ and $100 \mathrm{mg} /$ L). The range of $\mathrm{CaCl}_{2}$ contents tested here showed no effect on the survival of $P$. bursaria in the absence of fatty acid salts (data not shown). The decrease in toxicity was observed in three fatty acid salts, namely sodium oleate, palmitate and myristate in the presence of increasing contents of $\mathrm{Ca}$. In contrast, only sodium plamitate among the fatty acid salts showed the lowered toxicity in the presence of $\mathrm{Mg}$ (data not shown). However, for unknown reason, in both conditions, the cell survival rate was no longer high in the highest hardness $(400 \mathrm{mg} / \mathrm{L})$ in the range tested (data not shown).

\section{Acknowledgements}

Ionic chromatography was performed at the Instrumentation Center, The University of Kitakyushu. This work was supported by a grant-in-aid from the Fire and Disaster Management Agency of Japan and a grant-in-aid (16658031) by the Ministry of Education, Culture, Sports, Science and Technology, Japan. 
Bradlaw J. A. (1986), Evaluation of drug and chemical toxicity with cell culture systems. Fundam. Appl. Toxicol. 6, 598-606.

Kadono T., Shiota K., Tanaka M., Kawano T., Kosaka T., and Hosoya H. (2004), Effect of symbiotic algae on the growth kinetics in dark-grown Paramecium bursaria. Endocytobiosis Cell Res. 15, 63-70.

Kalmanzon E., Slotkin E., Cohen R., and Barenholz Y. (1992), Liposomes as a model for the study of the mechanism of fish toxicity of sodium dodecyl sulfate in sea water. Biochem. Biophys. Acta 1103, 148-156.

Kawano T., Kadono T., Fumoto K., Kosaka T., and Hosoya H. (2004a), Flow cytometric analysis of extreme euglenoid movements in Euglena gracilis: Effects of a sulfonylureic herbicide and hydrogen peroxide. ITE Letters on Batteries, New Technologies \& Medicine 5, 297-302.

Kawano T., Kadono T., Kosaka T., and Hosoya H. (2004b), Green paramecia as an evolutionary winner of the oxidative symbiosis: A hypothesis and supportive data. Z. Naturforsch. 59c, 538-542.

Kawano T., Kosaka T., and Hosoya H. (2005), Impact of a sulfonylureic herbicide on growth of photosynthetic and non-photosynthetic protozoa. In: Environmental Chemistry (Lichtfouse E., Schwarzbauer J., and Robert D., eds.). Springer-Verlag, Berlin, pp. 495-504.

Kirsner R. S. and Froelich C. W. (1998), Soaps and detergents: understanding their composition and effect. Ostomy/Wound Management 44, 62S-70S.

Kosaka T. (1991), Life cycle of Paramecium bursaria syngen 1 in nature. J. Protozool. 38, 140-148.

Miyoshi N., Kawano T., Tanaka M., Kadono T., Kosaka T., Kunimoto M., Takahashi T., and Hosoya H. (2003), Use of Paramecium species in bioassays for environmental risk management: determination of $\mathrm{IC}_{50}$ values for water pollutants. J. Health Sci. 49, 429-435.

Reisser W. (1992), Basic mechanisms of signal exchange, recognition, specificity, and regulation in endosymbiotic systems. In: Algae and Symbioses: Plants, Animals, Fungi, Viruses, Interaction Explored (Reisser W., ed.). Biopress, Bristol, pp. 657-674.

U.S. Environmental Protection Agency (2003), Ecotoxicology (ECOTOX) Database. http://www.epa.gov/ ecotox.

Wolf R., Wolf D., Tüzün B., and Tüzün Y. (2001), Soaps, shampoos, and detergents. Clin. Dermatol. 19, 353-397. 